\author{
Military Technical College \\ Kobry El-Kobbah, \\ Cairo, Egypt
}

\section{$9^{\text {th }}$ International Conference on Civil and Architecture Engineering ICCAE-9-2012}

\title{
STRUCTURAL BEHAVIOR AND INDUCED THERMAL STRESSES IN A UNIQUELY DESIGNED TOSHKA SPILLWAY REGULATOR Eehab A.B. Khalil*
}

\begin{abstract}
:
The current situation for the protection of the High Aswan Dam necessitated the revision of the current discharge capacity of the Toshka Weir. Due to the fact that it is expected to receive several high floods in Lake Nasser Reservoir and the restriction of passing high discharges (less than 700 milliom $\mathrm{m}^{3} /$ day) downstream the dam, a new spillway has been proposed to accommodate the newly established discharge in the Toshka Depression.
\end{abstract}

A description of the structure is described with propose d design alternatives. The location and requirements of operation imposed specific unique design criteria that are seldom implemented in other similar types of structures. These criteria are discussed including hot thermal stresses on the regulator and c hosen alternative is described.

Keywords:

Toshka Weir, floods, Lake Nasser Reservoir, Thermal Stresses

\section{INTRODUCTION:}

The High Aswan Dam is the most important structure for Egypt. The safety and flexible operation is a must against overtopping and brea ching. Because of the status of the Nile River in its downstream and its barrages, it was necessary to construct a spillway for the dam elsewhere. The Toshka depression was the choice for such area of spillage. A weir was constructed in an artificial canal between Lake Nasser and the depression. The initial design discharge capacity of the weir was estimated to be 250 million $\mathrm{m}^{3} /$ day. The actual discharge did not exceed 150 million $\mathrm{m}^{3} /$ day.

Due to the lack of discharge capacity for the weir, a regulator was suggested to accommodate such discharges and at the same time control the spillage during the water downfall stage in the Lake for

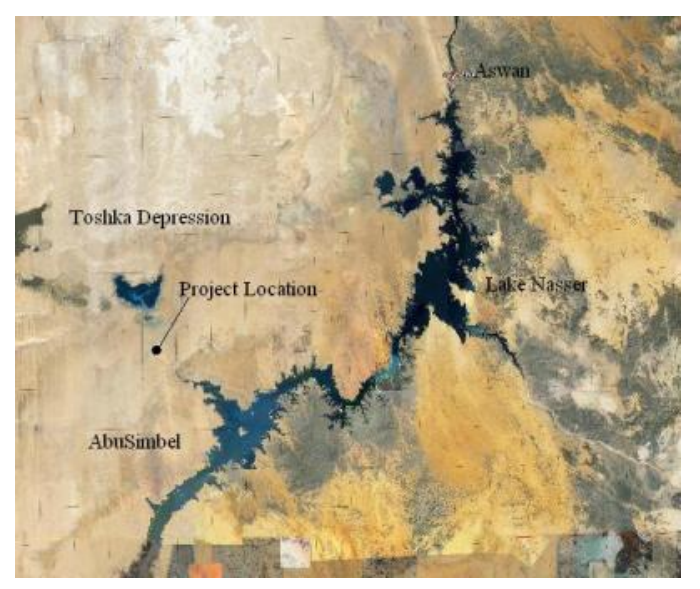

Fig 1: Project Location.

\footnotetext{
*Ass. Prof. Construction Res. Inst. National Water Res Cen, Kannater, Kaliobia,
} 
maximum actual water storage capacity.

\section{HYDRAULIC FEATURES:}

The existing Ogee type Weir is in very good structural condition even when under the harsh conditions of the desert and temperatures during prolonged dry seasons, but cannot accommodate the expected high volume of water discharges. The proposed location of a new regulator is at $\mathrm{km} 8.00$ of the Toshka canal. The regulator is sized to allow a discharge of 350 million $\mathrm{m}^{3} /$ day with $23 \times 15 \mathrm{~ms}$ free span vents. Any gate would be either fully closed or fully open or removed during dry season. There would not be any regulations except the ratio of opened vents to the total vents.

DESIGN CRITERIA:

The limiting design factors for such a structure are not commonly applicable for most of the regulators and barrages in Egypt. The location and circumstances necessitated special features to be considered in the design and construction phases:

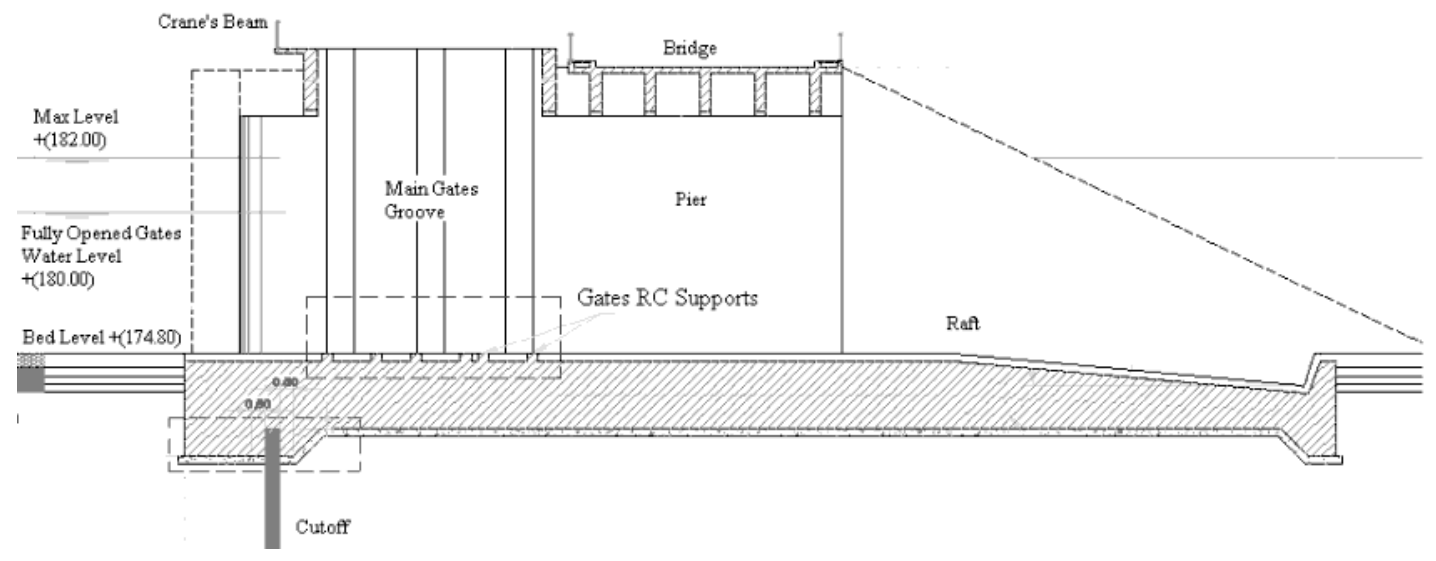

Figure 2: Elevation of the Proposed Toshka Spillway Regulator .

1- Most of the year, the regulator would be bed dry. The effect of temperature would be superimposed on all members especially the raft.

2- The gates would be stored aside and would be placed in vents when required.

3- Gates would be maintenance free and do not require special skills to install or remove. During maintenance with flow, gates would be used as stop logs.

4- The bridge and crane girders implement precast technique to allow construction during a flood.

5- The regulator allows further extension along its axis.

6- The regulator would be designed for the maximum water level and consideration of dry downstream is a strong option.

7- Piers were designed to resist vertical and horizontal forces considering $25 \mathrm{cms}$ on each face for erosion and protection and not considered in structural design.

8- It is very difficult to drive a steel sheet pile cutoff in the weak Nubian Sand Stone. Plastic concrete would be efficient to fill in the cracks in this weak stone.

\section{PROPOSED ALTERNATIVES for GATES:}

Several schemes of gates' arrangement have been suggested in the design stage: 
1. FLIPOVER GATES: The gate is stable until water reaches a certain level, where it flips over and floats away with the flow. It was refused because of its weight and could impact any area in the downstream causing damage or even death without warning. At the same time, the gates maybe damaged and require repair. This would require permanent transportation and cranes.

2. RADIAL GATES: They are efficient in controlling water discharge downstream and water levels upstream with sophisticated mechanisms. They are light with respect to size, but cover a large plan. They require maintenance and high skills in installation and operation. They are not cheap and would increase total project cost with no real benefit during operation. They do not have the benefit of stow -away storage during the dry season.

3. VERTICAL ARCHED GATES: Because of size and head difference, arched gates were considered. They are efficient weight wise and have less print than that of the radial gates and could be moved away. They yet have the disadvantage of increasing the overall cost of the structure.

4. VERTICAL LIFT GATES: They are commonly used in Egypt such as the Henin Gates. They work permanently or temporarily. They are near maintenance free and could be handled easily with an over head crane. Th is type of gate was considered the most suitable for such regulator configuration.

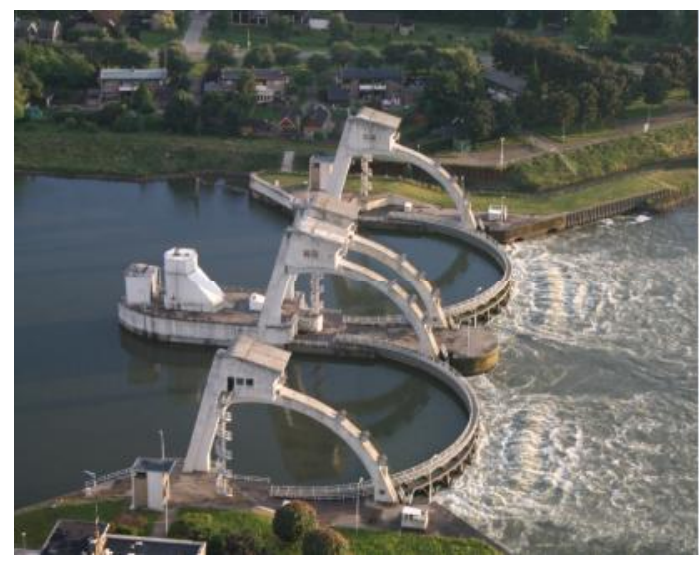

Fig 3: Vertical Arched Gates (Holland).

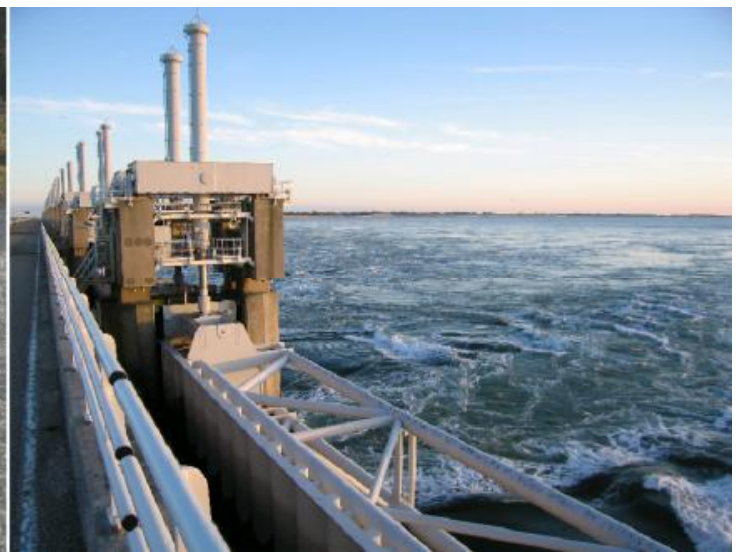

Fig 4: Vertical Lift Gates (Delta Project).

\section{FINAL PROPOSED DESIGN for GATES:}

The chosen type of gate would be a vertical lift of 2 horizontal leaves resting on each other. The lower and upper leaves of the gates would be designed of equal weight. It was estimated that if the gate is of one leaf it would weigh about $80+$ tons which would be considered quite heavy. For such span, the common weight for each gate leaf would be about 49tons.

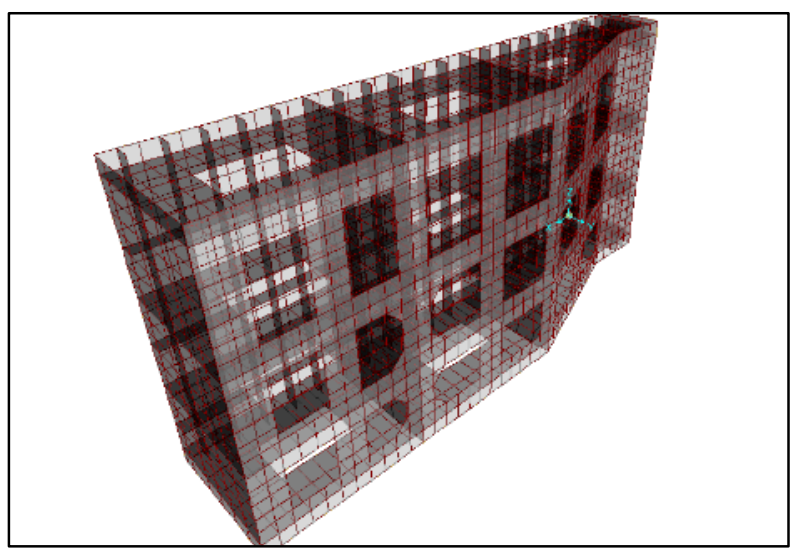

Fig 5: 1/2 Model for Lower Leaf of Gate. 


\section{DETAILS RAFT DESIGN UNDER THERMAL LOADS:}

The raft is $42 \mathrm{~ms}$ wide and is $80 \mathrm{~ms}$ between expansion joints. Expansion joints were detailed to allow horizontal movement due to temperature variation, but would work together for vertical straining actions. Differential settlement between the edges of the expansion joints was not allowed. In addition, the construction joints were situated to allow for economical use of a $1000 \mathrm{~m}^{3} /$ day capacity mixer with a $50 \%$ day use because of the heat in such area.

A $25 \mathrm{cms}$ protective layer was for erosion and high temperature resistant concrete. There would be concrete studs to support the gates weight whe $\mathrm{n}$ placed in the vents.

To choose the location of the expansion joints, a preliminary investigation of the thermal straining action was carried out on the raft. The heat is so intense during daylight exceeding $50^{\circ} \mathrm{C}$ in the shade. It could be reduced to less than $10^{\circ} \mathrm{C}$ during the night. It was recommended to apply a variation of external $30^{\circ} \mathrm{C}$ on the raft for such extreme temperatures. Since the raft is a water section, tensile stresses from the thermal variations were not allowed to exceed Fig 6: Sap Model for Raft and the Piers. The tensile capacity of the concrete. However, since the raft sustains flexural capacities from the superimposed permanent loads, it is imperative to choose the expansion joints as such that the tensile stresses do not exceed the $15 \%$ increase in the sustained tensile stresses from the sustained loads. For the common reinforced concrete tensile capacity of $17 \mathrm{~kg} / \mathrm{cm}^{2}$, the additional stresses should not exceed about $3.00 \mathrm{~kg} / \mathrm{cm}^{2}$.

A numerical structural model for the raft was carried out applying such uniform variation in temperature on shells supported by the stiff springs of the weak rocks beneath. From a total raft length of $420 \mathrm{~ms}$ to a reduced raft length of $40 \mathrm{~ms}$ were modeled. The variation in the axial tensile forces was near linear with the raft length. The flexural straining actions due to the thermal loads did not vary much regardless of the raft length due to thermal loads. The axial tensile forces was about $600 \mathrm{ton} / \mathrm{m}$ width for the $420 \mathrm{~ms}$ to a mere $8 \mathrm{ton} / \mathrm{m}$ width for the $40 \mathrm{~ms}$ long raft.

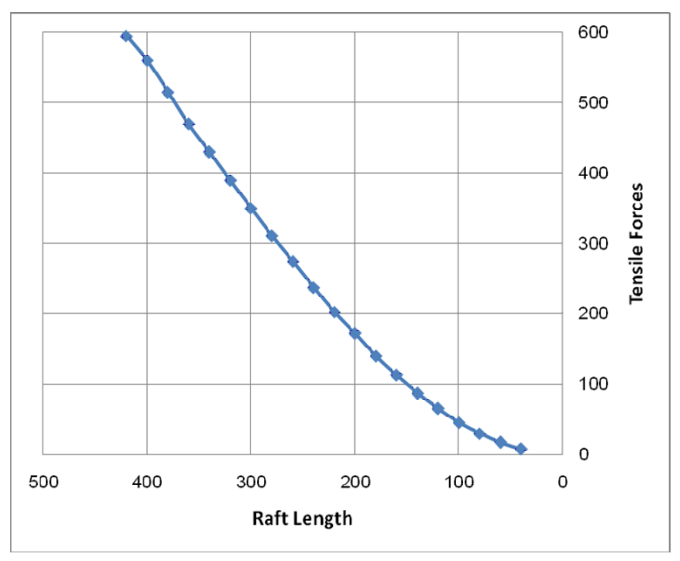

Fig 7: Raft Length vs Tensile Forces.

The tensile stresses vary depending on the raft thickness. It is constant in the area supporting the piers with a thickness of $250 \mathrm{cms}$ and vary to $95 \mathrm{cms}$ raft thickness at the downstream tip of the raft before the endsill. The thickness does not include the protective layers on top of the raft. For the

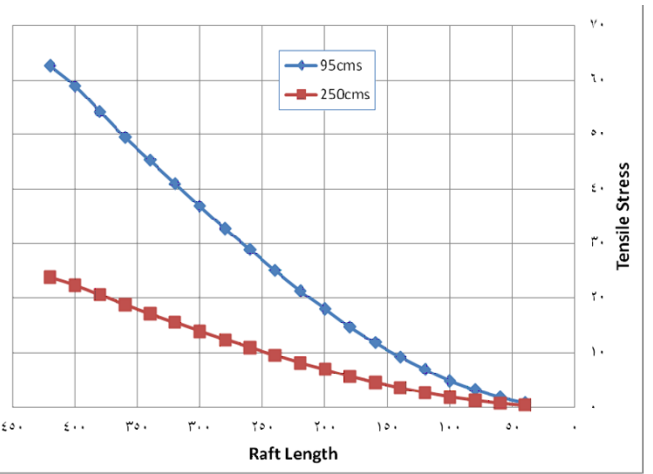


$250 \mathrm{cms}$ thick raft, the additional tensile stresses in the raft vary between $23.80 \mathrm{~kg} / \mathrm{cm}^{2}$ for $420 \mathrm{~ms}$ raft length to $0.32 \mathrm{~kg} / \mathrm{cm}^{2}$ for $40 \mathrm{~ms}$. For the $1.00 \mathrm{~ms}$ thick raft, the additional tensile stresses in the raft vary between $62.63 \mathrm{~kg} / \mathrm{cm}^{2}$ for $420 \mathrm{~ms}$ raft length to $0.842 \mathrm{~kg} / \mathrm{cm}^{2}$ for $40 \mathrm{~ms}$.

Fig 8: Raft Length vs Tensile Stresses.

Table 1: Tensile Stresses vs. Raft Length and Thickness.

\begin{tabular}{|l|l|l|l|l|l|l|l|l|l|r|}
\hline & 420 & 400 & 380 & 360 & 340 & 320 & 300 & 280 & 260 & 240 \\
\hline 95 & 62.63 & 58.95 & 54.21 & 49.47 & 45.26 & 41.1 & 36.84 & 32.74 & 28.95 & 25.05 \\
\hline 250 & 23.80 & 22.40 & 20.60 & 18.80 & 17.20 & 15.6 & 14.00 & 12.44 & 11.00 & 9.52 \\
\hline
\end{tabular}

\begin{tabular}{|c|c|c|c|c|c|c|c|c|c|c|}
\hline & 220 & 200 & 180 & 160 & 140 & 120 & 100 & 80 & 60 & 40 \\
\hline 95 & 21. & 18.1 & 14.7 & 11.8 & 9.2 & 60 & 48 & 3 & 18 & - \\
\hline 250 & 8.12 & 6.88 & 5.60 & 4.52 & 3.52 & 2.64 & 1.84 & 1.22 & 0.70 & 0.32 \\
\hline
\end{tabular}

In the transverse direction, the tensile stresses did not vary much whether the raft is long or short. From analysis, the tensile stresses shows directional dependance behavior. It does state that the thermal behavior depends on the length rather than the projected area of the member.

In the choice of the location of the expansion joint, it is very difficult to vary its location along the width of the raft depending on the thickness. For the $250 \mathrm{cms}$ thick raft, the expansion joints would be at reasonable intervals of about $130 \mathrm{~ms}$. For the $95 \mathrm{cms}$ thick raft, the expansion joints would be at intervals no more than $80 \mathrm{~ms}$. Despite the fact that the solid length of the raft exceeded twice that allowed by specification s (40ms), it is feasible to reduce the number of expansion joints with such analysis for a reasoned thickness of the raft. It is expected for less thicknesses, that the intervals for the expansion joints would be less spaced. In addition, the expansion $\mathrm{j}$ oints in the raft must be at such to not restrain the bridge from its horizontal movement along its axis.

\section{CONCLUSIONS:}

1- $\quad$ For reasonably sized regulator's thick raft, a double distance by specifications between the expansion joints is allowed under high external thermal loadings. This is applicable for uniformly foundation soil underneath.

2- $\quad$ Sizing the distances between the expansion joints would be limited to the additional allowed tensile stresses in the studied member.

3- $\quad$ From such simple analysis, the mi nimum required reinforcement for thermal stresses may be reduced than that required by specifications for thick members. This reinforcement may not be reduced to zero, unless the raft is commonly cooled and does not require reinforcement from the permanen $t$ sustained loads.

4- $\quad$ The less restrained thick concrete members for irrigation structures, the longer is allowed a distance between the expansion joints without relative increase in required reinforcement for the members.

\section{RECOMMENDATIONS:}


It is imperative to study massive structures under external thermal loads with all its details in comprehensive numerical models to reduce the required necessary reinforcement and location of expansion joints as much as possible. It is preferred to limit the allowed tensile stresses to that allowed by code as additional tensile stresses for temporary loads.

\section{ACKNOWLEDGEMENT:}

The author would like to thank the opportunity that allowed him to receive such experience from the High and Old Aswan Dam Authority, Ministry of Wa ter Resources and Irrigation. He wishes to thank all of those that contributed in one way or another to the completion of such work. The work, ideas, suggestions, discussions and implementation is greatly appreciated.

\section{REFERENCES:}

1- M. Sobaih, R.M. Kebeasy and K.A. Ahmed, "Development of Seismic Hazard Maps of Egypt." International Journal of Earthquake Engineering, v2n1, Jan 1992.

2- "Increasing the Storage Capacity of the Toshka Depression and Possibility of Usage." Hydraulic Research Institute, Aug 2005.

3- "Specifying the Environmental Aspects of the Toshka Spillway Regulator." Meteriological Changes and Environmental Researc Institute, Apr 2004.

4- "Geophysical Studies on the Proposed Site of Tushka Control Barrage (on the Spillway Canal." National Research Institute of Astronomy and Geophysics. April 2004.

5- "The Hydraulic Design of the Toshka Spillway Regulator at Km 8.00." Hydraulic Research Institute, Mar 2003. 